\title{
EL INNATISMO DE LEIBNIZ*
}

\section{ALEJANDRo HERRERA IbáÑEZ}

INSTTTUTO DE INVESTIGACIONES FILOSÓFICAS Universidad Nacional AưtónOMa de MÉxico

En el presente trabajo mostraré que hay dos rasgos en la teoría innatista leibniziana de las ideas que bacen que dicha teorta llame poderosamente la atención boy dia. ${ }^{l}$ Dichos rasgos son de tal naturaleza que me llevarán a caracterizar el innatismo de Leibniz como lo que llamaré un innatismo disposicional y un innatismo proposicional. Mostraré también que hay en la doctrina leibniziana un innatismo que llamaré global y otro que llamaré restringido. El primero fue brevemente formulado por Leibniz en 1686, en el Discurso de metafisica, y el segundo fue detalladamente expuesto alrededor de 1703 en los Nuevos ensayos.

\section{I}

Leibniz empieza a articular con claridad su teoría epistemológica de las ideas a partir de 1678, en su ensayo titulado ¿Qué es una idea? Añade algunas precisiones en 1684, en sus Meditaciones sobre el conocimiento, la verdad y las ideas.

Formula un innatismo en 1686 , en el Discurso de metafisica, y desarrolla otro alrededor de 1703 en adelante, en los Nuevos ensayos.

En su breve ensayo ¿Qué es una idea?, de 1678, Leibniz hace cuatro aproximaciones a su noción de idea. En la primera aproximación establece el carácter mental de las ideas:

* Este trabajo fue presentado el 10 de agosto de 1989 en el VIII Simposio de Filosofía, organizado por el Instituto de Investigaciones Filosóficas, y fue elaborado en el Seminario de Historia de la Filosofía del mismo Instiruto.

1 Estos dos rasgos - la aceptación de proposiciones, y no sólo de ideas innatas, por un lado, y su caracterización como disposiciones, por el otro lado- pueden verse claramente, por ejemplo, en el innatismo chomskyano, el cual, mediante la noción de "competence" introduce el elemento disposicional para explicar la generación de propasiciones, cuyas estructuras se encuentran presentes en una mínima gramática innata que nos permite comprender y producir oraciones. Para ver que la teoría leibniziana ha llamado la atención actualmente en relación con las nuevas teorías, véase Hierro (cap. 4, en particular la sec. 4.3), "Las ideas innatas en Leibniz”. Pueden verse también los cinco artículos, en Cortés, sobre "El lenguaje y las ideas innatas", especialmente los de Lenneberg, Piaget y Chomsky, y el libro de Sells. 
Por el término idea entendemos algo que está en nuestra mente. (L 207)

En la segunda aproximación Leibniz aclara que este algo no necesita ser algo actualmente presente en la mente:

Una idea consiste, no en algrin acto, sino en la facultad de pensar. (Ibid.)

Pero Leibniz es consciente de que la noción de fucultad de pensar es problemática, pues en un sentido amplio tendríamos ideas de cualquier cosa en virtud de la facultad "remota" de pensarlas, aun cuando no podamos tenerlas. Por tanto,

la idea requiere de cierta facultad "cercana" o habilidad para pensar sobre una cosa. (Ibid.)

Esta habilidad o facultad "cercana" consiste en la posesión de algún método para llegar al objeto (ibid.). En ello consiste la tercera aproximación. Pero aún no es suficiente, piensa Leibniz. Es necesario que aquello a lo que se puede llegar mediante algún método pueda ser expresado:

Debe haber algo en mí que no solamente me lleve a la cosa sino que también la exprese. (Ibid.),

con lo cual tenemos la cuarta aproximación. El cuadro final, por tanto, consiste en que la idea es mental, pero no actual, sino una posibilidad real de representar algo.

Desde aquí se ve ya que las ideas no son para Leibniz algo así como "cosas en la cabeza". En 1686 dirá, en el Discurso, que

podemos ... definir nuestra esencia o idea como aquello que incluye todo lo que expresamos. (L 314)

De ello se sigue que ningún acto de pensamiento agota el objeto representado, puesto que no lo expresa en su totalidad. Las ideas no son lo mismo que las imágenes o que los pensamientos (esto se verá posteriormente en Leibniz con mayor claridad). Pero tampoco son iguales a los conceptos, puesto que para Leibniz toda idea debe ser lógicamente posible y, por tanto, no contradictoria, lo cual no excluye que lo lógicamente imposible pueda ser pensado. Leibniz hace tal distinción en el Discurso, $§ 23$ :

Un uso erróneo de las ideas es ocasión de varios errores, pues cuando uno razona sobre algo, se imagina que tiene una idea de esa cosa, y ésta es la base sobre la que ciertos filósofos, antiguos y modernos, han construido una de las demostraciones de Dios, que es sumamente imperfecta, pues debo tener una idea de Dios, 
dicen ellos, o de un ser perfecto, ya que pienso en él, y no se puede pensar sin una idea ... Pero puesto que a menudo pensamos en quimeras imposibles ... este razonamiento es insuficiente. En este sentido, entonces, podemos decir que hay ideas verdaderas y falsas, según que la cosa involucrada sea o no posible. Así pues, uno puede jactarse de tener una idea de una cosa solo cuando está seguro de su posibilidad. (L 318) (Las cursivas son mías.)

Es decir, las ideas falsas no son ideas, pero ello no les resta carácter mental. Puesto que pueden ser concebidas, Leibniz las llama concepto:

No tenemos idea de un concepto cuando éste es imposible ... Es ... sólo cuando nuestro conocimiento de conceptos confusos es claro y nuestro conocimiento de conceptos distintos es intuitivo, que vemos sus ideas totales. (L 319)

Las ideas para Leibniz son tales cuando son claras, intuitivas y posibles. El mundo de lo contradictorio, o de lo confuso, o de lo no intuitivo, está reservado para los conceptos o nociones. Así en noviembre de 1684 decía:

No percibimos las ideas aun de aquellas cosas que conocemos distintamente, excepto en la medida en que usamos el pensamiento intuitivo... No es verdad, o. al menos es ambiguo, decir, como algunos dicen, que no podemos hablar de nada ni entender lo que decimos sin tener una idea de ello. (L 292)

Una idea es verdadera cuando es concepto es posible; es falsa cuando implica contradicción. (L 293)

Las expresiones que están en el alma, sean o no concebidas, pueden ser llamadas ideas, pero aquellas que son concebidas o formadas pueden ser llamadas nociones o conceptos. (L 321)

Como se puede apreciar, en 1678 y 1684 Leibniz va despejando el camino hacia el innatismo. Para ello insiste en que las ideas no tienen que ser actuales, y encuentra, también en 1684, una metáfora que le será muy útil:

Hay también en nuestra mente ideas de cosas que no estamos pensando actualmente, así como la figura de Hércules se encuentra en el mármol no trabajado. (L 294)

Si las ideas no tienen por qué ser actuales, ¿son entonces algo así como “cosas almacenadas” en el alma? La metáfora de Hércules presente en el mármol no trabajado nos indica que no es así. No son, por así decirlo, imágenes ya formadas esperando su turno para salir al escenario iluminado de la conciencia. Es en 1686, en en el Discurso § 26, cuando Leibniz encontrará el término que necesita. Son -nos dirá-disposiciones. He aquí el pasaje:

Nuestra alma siempre tiene dentro de ella la disposición a representarse cualquier nanuraleza o forma cuando surge la ocasión de pensar en ella ... esta dispasición de 
nuestra alma, en la medida en que expresa alguna naturaleza, forma o escencia, es propiamente la idea de la cosa, la cual está en nosotros y siempre está en nosotros, ya sea que pensemos en ella o no. (L 320) (Las cursivas son mías.)

Sólo le falta a Leibniz decir, con todas sus letras, que dicha disposición es innata, pero aunque no lo hace así, en lo que sigue del pasaje no queda ya la menor duda de que se encuentra en terreno innatista:

Nuestra alma expresa a Dios y al universo, y a todas las esencias así como a todas las existencias ... nada entra naturalmente en nuestras mentes desde afuera ... como si /nuestra alma/ tuviera puertas y ventanas. Tenemos todas estas formas en nuestras propias mentes, y aun desde la eternidad ... nada se nos puede enseñar cuya idea no esté ya en nuestra mente. (Ibid.) (Las cursivas son mías.)

Naturalmente, para explicar tan maravilloso conocimiento del universo desde el nacimiento mismo, Leibniz contaba - como todos los racionalistas de la época - con la también maravillosa ayuda de Dios, quien, gracias a su acción continua, hace posible que nuestra alma exprese todo el universo, incluyendo a Dios mismo:

Vemos todas las cosas a través de él; por ejemplo, cuando vemos el sol y las estrellas, es Dios quien nos lo ha dado y quien preserva en nosotros sus ideas. (L 321)

Conviene notar aquí que en estos pasajes de 1686 Leibniz se compromete con un innatismo muy fuerte, que se deriva de su incipiente concepto de mónada cerrada, sin puertas ni ventanas, de la que no hablará ampliamente sino hasta 1714. Estando el alma totalmente incomunicada, absolutamente todas las ideas tienen que ser innatas y provenir de Dios. Esto le creará obviamente problemas a un Leibniz influido por la escolástica e interesado en rescatar lo mejor de ella. Pero no será sino hasta aproximadamente 18 años después, cuando Leibniz volverá sobre el problema.

Es aproximadamente en 1703, al redactar los Nuevos ensayos, para responder al aristotelismo lockeano que ve al alma como una tabula rasa, cuando Leibniz formula su teoría innatista restringida. En ella no todas las ideas son innatas, sino sólo algunas (Prefacio y I, 1/E 40,74). El alma no es vista como una mónada cerrada, sin puertas ni ventanas, sino como capaz de recibir información del exterior a través de los sentidos, en el caso de las ideas no innatas. En cuanto a las ideas innatas, los sentidos desempeñan también un papel, como veremos adelante. 
Un rasgo importante de la formulación restringida es que Leibniz no se limita a hablar de ideas, sino que incluye también las que llama proposiciones, principios o verdades. En varias listas, que no pretenden ser exhaustivas, de ideas innatas, cuyos objetos son inmediatos a nuestro entendimiento (Prefucio /E44), Leibniz menciona las ideas de unidad, duración, cambio, acción, percepción, placer (ibid.), Dios (I, 1/E74, señalando estar de acuerdo con Descartes), posible, mismo (I, 3/E107), todo, parte, número, extensión (I, 3/E108), ser (Prefacio /E44; I, 3 /E108), sustancia (Prefacio /E44; I, 3 /E112), virtud (I, $3 / \mathrm{E} 111$ ), y los números (I, 1/E83). Poniendo estos últimos como ejemplo, llama intelectuales a dichas ideas $(\mathrm{I}, 1 / \mathrm{E} 82,88)$, y les asigna la característica de dar origen a las verdades necesarias (I, 1 /E82). En otro lugar las llama también ideas de reflexion (I, l /E88), lo cual se entiende perfectamente, pues las verdades necesarias son a menudo llamadas por Leibniz en sus escritos verdades de razón, las cuales son también para él innatas, por originarse de ideas innatas. Así, dice que

todas las verdades que se pueden deducir de los conocimientos innatos primitivos pueden a su vez ser denominadas innatas, porque el espíritu las puede extraer de su propio fondo. (I, 1 /E79).

En las listas de proposiciones necesarias innatas, Leibniz incluye las de las matemátias puras (particularmente la aritmética y la geometría), las de la lógica, las de la metafísica (que da forma a la teología) y las de la moral (que da forma a la jurisprudencia) (Prefacio /E42). Señala también como innata la proposición "Dios debe ser adorado" (probablemente sería ésta para Leibniz una proposición de la moral). También señala como innatos el principio de identidad y el principio de no contradicción (I, l /E77). Aparte enfatiza que toda la aritmética y la geometría son innatas (I, 1 /E78). Digo que enfatiza porque podía (y debía) decir lo mismo de toda lógica, toda la metafísica y toda la moral, pero probablemente Leibniz veía que esto último no era tan claro. Es quizás por ello que en otro pasaje dice por boca de su personaje Teófilo que sólo las proposiciones de la aritmética y de la geometría son necesarias (I, 1 /E89), es decir, son las que más claramente poseen lo que Leibniz llama necesidad absoluta, geométrica o metafísica (II, 21 /E207) - que es la necesidad que caracteriza a las verdades de razón- en oposición a la que llama necesidad hipotética, física o moral (Ibid.) - que es la necesidad que caracteriza a las verdades de hecho. Pero todas las verdades innatas son verdades de razón; luego, deben todas -incluyendo las de la metafísica y la moral- poseer necesidad absoluta, geométrica o metafísica, y no necesidad hipotética, física o moral.

He aquí una reconstrucción tentativa del cuadro que nos pinta Leibniz: 


\section{IDEAS Y PROPOSICIONES INNATAS EN LOS NUEVOS ENSAYOS}

\begin{tabular}{|c|c|c|c|c|}
\hline $\begin{array}{l}\text { Matemáticas puras } \\
\text { número } \\
\text { los números } \\
\text { extensión } \\
\\
\end{array}$ & Logica & $\begin{array}{l}\text { Metafisica } \\
\text { ser } \\
\text { sustancia } \\
\text { duración } \\
\text { cambio } \\
\text { acción } \\
\text { percepción } \\
\text { sible } \longrightarrow\end{array}$ & $\begin{array}{l}\text { Moral } \\
\text { placer } \\
\text { virtud }\end{array}$ & $\begin{array}{l}\text { ideas intelectuales o } \\
\text { puras (distintas) }\end{array}$ \\
\hline $\begin{array}{l}\text { proposiciones } \\
\text { aritméticas y } \\
\text { geométricas }\end{array}$ & 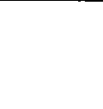 & $\begin{array}{l}\text { "Dios debe ser } \\
\text { adorado" }\end{array}$ & & $\begin{array}{l}\text { proposiciones } \\
\text { necesarias }\end{array}$ \\
\hline
\end{tabular}

Como se habrá visto ya, hemos llamado proposicional al innatismo de Leibniz porque incluye proposiciones, no porque excluya las ideas.

El otro rasgo importante del innatismo leibniziano consiste en el carácter disposicional de las ideas y proposiciones innatas. En los Nuevos ensayos acude Leibniz nuevamente a la metáfora del mármol, añadiéndole un componente que lo hace preferirla a la metáfora de 1684. Dice:

Por eso prefiero utilizar la comparación con una piedra de mármol que tiene vetas, mejor que una piedra de mármol totalmente compacta, o tablillas vacías, es decir, lo que los filósofos llaman tabula rasa. Pues si el alma se pareciese a dichas tablillas vacías, las verdades estarían en nosotros como la figura de Hércules está en un mármol, siendo así que a dicho mármol le es completamente indiferente recibir esa figura o cualquier otra. Mas si en la piedra existiesen vetas que marcasen la figura de Hércules con preferencia a otras figuras, dicha piedra estaría más determinada a ello, y de alguna manera Hércules estaría como innato, aun cuando hiciese falta tomarse trabajo para descubrir esas vetas, y para limpiarlas mediante el pulimento, quitando lo que les impide aparecer. Y así es como las ideas $y$ las verdades nos son innatas, en tanto inclinaciones, disposiciones, hábitos o virtualidades naturales, y no como acciones. (Prefacio /E44) (Las cursivas son mías.)

Estas "vetas" constituyen lo que más adelante también llama aptitudes, preformaciones (I, 1/E82), o conocimiento virtual (I, 1 /E89). Dicho carácter virtual, habitual o disposicional de las ideas y proposiciones innatas, las diferencia de los pensamientos, los cuales son acciones y no hábitos o disposiciones. Éstos pueden pasar desapercibidos, mas no aquellos (I, 1 /E89-90). Se desprende que las verdades no son pensamientos (I, l /E90), pues hay más verdades que el número de pensamientos que cada uno de nosotros pueda tener en un momento dado (ibid.). Lo mismo vale para las imágenes sensi- 
bles respecto de las ideas puras (I, $\mathrm{f} / \mathrm{E} 78$ ) o intelectuales. Cuando la veta aflora - sea ésta idea o verdad-, se manifiesta en la superficie como imagen o como pensamiento. $\mathrm{Y}$ aquí es donde da Leibniz a los sentidos un papel que desempeñar. Los sentidos son, por así decirlo, disparadores del proceso de transformación de la idea en imagen y de la verdad, principio o posición en pensamiento, o para decirlo en otra terminología leibniziana, de la percepción en apercepción. ¿Cómo se lleva a cabo este proceso?

Leibniz acepta que, en cierto sentido, los sentidos son "causa en parte de nuestros pensamientos" (I, 1 /E74), y dicho sentido queda mejor expresado - para él diciendo que son ocasiones para pensar (Prefacio/E42) las ideas y verdades innatas. Los sentidos no originan dichas verdades, sino que sólo le sirven a éstas de punto de apoyo (I, l /E79), pues no hay ninguna conexión necesaria entre lo sensible y las verdades de razón (ibid.). Estas verdades se originan en el entendimiento (I, I /E75), pues

todos los pensamientos y acciones de nuestra alma provienen de su propio fondo, sin que los sentidos se las puedan proporcionar (I, 1 /E74),

y, por así decirlo, somos "innatos a nosotros mismos" (Prefacio /E44).

Las verdades de hecho sí se originan en las experiencias de los sentidos y en nuestras percepciones confusas (I, l /E75) dejando de ser meros puntos de apoyo, pero las verdades de hecho carecen de necesidad absoluta, porque la inducción no garantiza necesidad (I, l /E82), ya que los sentidos no tienen fuerza demostrativa (ibid.), debido a que sólo proporcionan datos particulares o individuales (Prefacio /E41). Los sentidos son, pues, condiciones necesarias pero no suficientes del conocimiento (Prefucio /E41; I, l /E81). Sólo la razón puede dar reglas seguras (Prefucio /E43), pero aunque los experimentos no originan la razón, sí la confirman (Prefacio /E42) o verifican (I, l /E87).

Finalmente, hay que hacer notar que lo que en 1678 Leibniz llamaba facultad remota, en los Nuevos ensayos es llamado simplemente facultad, y lo que llamaba facultad cercana es llamado disposición (I, l/E81, 87). Es por ello que también he llamado a este innatismo innatismo disposicional.

Consideraremos ahora algunos problemas relacionados con el innatismo leibniziano.

El primer problema consiste en que hay dos clases de innatismo en Leibniz, el global y el restringido, y entonces parecería que o bien Leibniz se contradijo o bien que abandonó uno para abrazar el otro. Afortunadamente, podemos obtener la respuesta del mismo Leibniz. Al inicio del diálogo entre Teófilo y Filatetes en los Nuevos ensayos, Teófilo —o sea, Leibniz-, después de aceptar junto con Descartes que la idea de Diós es innata, agrega: 
En la actualidad voy todavía más lejos, en conformidad con el nuevo sistema, hasta el punto de creer que todos los pensamientos y acciones de nuestra alma provienen de su propio fondo, sin que los sentidos se las puedan proporcionar. (I, l /E74) (Las cursivas son mías.)

(El "nuevo sistema" es obviamente el que años después, en 1714, resumiría en la Monadología.) E inmediatamente añade:

Pero. . acomodíndome a los modos de expresión usuales, ya que efectivamente son buenos y sostenibles... examinaré de que manera se debe, según mi opinión, decir, también según el sistema corriente... que hay ideas y principios que no provienen de los sentidos... aunque los sentidos nos proporcionan la ocasión de apercibirnos de su existencia. (ibid.) (Las cursivas son mías.)

Se ha señalado a este respecto que Leibniz es ambiguo (Hierro 79). Pero si se lee con mayor cuidado, la ambigüedad desaparece. Leibniz declara ser partidario del innatismo global, e insinúa que en el pasado se adhirió al innatismo restringido, probablemente cuando aún no desarrollaba cabalmente su concepto de mónada. Pero, puesto que en la mesa de discusión tiene frente a sí a un antiinnatista como Locke, le bastará con que éste acepte un innatismo restringido. Ya llegaría el momento -de haberse dado la discusión, que no tuvo lugar - de dar un paso más y demostrar que si bien el innatismo restringido es bueno y defendible, el innatismo global es aún mejor y totalmente satisfactorio. Leibniz pensó probablemente que introducir el concepto de mónada habría sido en ese momento demasiado, y habría quizá llevado a una ruptura de la discusión. Por ello es que prefiere jugar con las cartas de su interlocutor, para probarle que aún en su propio terreno hay una forma defendible de innatismo.

Surge un segundo problema si nos preguntamos si para Leibniz es o no innato su principio de razón suficiente. Puesto que éste es sin duda un principio metafísico, Leibniz habría dicho que se trata de una verdad innata y absolutamente necesaria, dado que es una verdad de razón. Ahora bien, para Leibniz todas las verdades de hecho - de las que dice en los Nuevos ensayos que se originan en los sentidos- se fundan en el principio de razón suficiente. Pero como sostiene también que lo que se deriva de lo innato es también innato (I, l /E79), tendría que aceptar que todas las verdades de hecho son también innatas. Se explica así que no mencione el principio de razón suficiente en los Nuevos ensayos, pues de haberlo hecho se habría visto llevado a defender el innatismo global y no el innatismo restringido que en ese momento le interesaba que su interlocutor aceptase. En realidad, Leibniz le estaba obsequiando a Locke un caballo de Troya, pero un caballo que también le habría acarreado ciertas complicaciones, pues habría tenido que aceptar que, al fundarse en el 
principio de razón suficiente, que es una verdad que posee necesidad absoluta, todas las verdades de hecho poseen también necesidad absoluta, y no la necesidad hipotética, física o moral que les adjudicó.

El tercer problema se lo plantea Leibniz mismo por boca de Filatetes mediante una objeción que éste hace a Teófilo. En la parte más interesante de la objeción argumenta Filatetes que no sólo las ideas intelectuales producen proposiciones necesarias, sino también las ideas sensibles; por ejemplo, "el blanco no es el rojo" o "lo amargo no es lo dulce" (I, l /E83). La intención de la objeción es concluir que las ideas de los colores, sabores, o sea, de los datos inmediatos de los sentidos, son innatas. Además, dice la objeción, se sigue que hay un número infinito de proposiciones innatas de este tipo (I, 1 /E84), y agrega:

Si tenemos en cuenta, además que una proposición no puede ser innata a menos que lo sean las ideas que la componen, habrá que suponer que todas las ideas que tenemos de colores, sonidos, gustos, figuras, etc., son innatas. (I, 1 /E84) (Las cursivas son mías.)

El argumento intenta mostrar la necesidad de las proposiciones en cuestión, asume que todas las proposiciones necesarias son innatas y apela al principio de que si una proposición es innata, sus componentes son innatos. Leibniz aceptaría que todas las proposiciones necesarias son innatas si se trata de la necesidad absoluta y no de la necesidad hipotética, pero prefiero no decir nada al respecto. Su ataque se dirige a la supuesta aplicación del principio mencionado. Al provenir de los sentidos, las ideas de color, sabor, etc., no son innatas; luego, las proposiciones en que entran tampoco son innatas. Sin embargo, parece aceptar que dichas proposiciones son necesarias por ser aplicaciones del principio de no contradicción; pero no dice qué tipo de necesidad tienen (I, 1 /E84).

Filatetes ha puesto en un buen aprieto a Leibniz. Al principio de que de lo innato se sigue lo innato, Leibniz opone ahora el concepto de aplicación de un principio y un nuevo principio: el de que si una proposición es innata, sus componentes son innatos. Hay aquí una tensión que Leibniz no resuelve limpiamente, y mi suposición es que no lo hace así porque está tratando de mantenerse dentro de la estrategia de defender únicamente el innatismo restringido. De lo contrario, se arrojará presuroso en brazos del innatismo global, consiguiendo únicamente asustar a los lockeanos y que rechacen su caballo de Troya. 


\section{BIBLIOGRAFIA}

Cortés, Alonso (ed.), Lecturas de lingüistica, Cátedra, Madrid, 1989.

Hierro S. Pescador, José, La teoria de las ideas innatas en Chomsky, Labor, Barcelona, 1976.

Leibniz, Gottried Wilhelm, Pbilosophical Papers and Letters, editado por Leroy E. Loemker, 2a. ed., Reidel, Dordrecht-Boston, 1976.

-, Nuevos ensayos sobre el entendimiento bumano, ed. preparada por Javier Echeverría Ezponda, Editora Nacional, Madrid, 1983.

Sells, Peter, Lectures on Contemporary Symtatic Theories, Center for the Study of Language and Information, Stanford, 1985. [Trad. de Ramón Cerdá: Teorias sintácticas actuales, Teide, Barcelona, 1989.] 